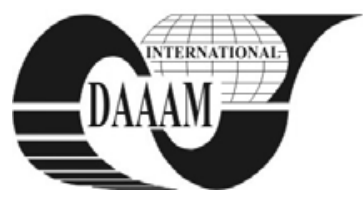

Annals of DAAAM for 2011 \& Proceedings of the 22nd International DAAAM Symposium, Volume 22, No. 1, ISSN 1726-9679 ISBN 978-3-901509-83-4, Editor B. Katalinic, Published by DAAAM International, Vienna, Austria, EU, 2011 Make Harmony between Technology and Nature, and Your Mind will Fly Free as a Bird

\title{
DETERMINATION OF THE STRESS CONCENTRATION FACTOR USING FEM
}

\author{
DURIS, R[astislav] \& LABASOVA, E[va]
}

\begin{abstract}
One of the important input parameters necessary for fatigue analysis of structures is the stress concentration factor which takes into account stress rise around a notch or some other sudden discontinuity of the component cross-section. For normalized shapes of notches, the values of the stress concentration factors are determined analytically and available in the literature. The paper deals with determining the stress concentration factor for basic load cases and non-standard shapes of a notch using FEM
\end{abstract}

Key words: fatigue analysis, stress concentration factor, FEM

\section{INTRODUCTION}

To the important loading case of the machine components can be included the cyclic load, when mechanical stress changes cyclically around the mean stress with some amplitude. This may lead to a damage of components due to fatigue and to the fatigue fracture. The most frequently locations of critical area in the components are generally shoulders, grooves, notches, keyways, holes, threads, etc. These sudden changes of crosssection give rise to stress peak, which can lead to shorten life of the components due to fatigue. Such localizations of higher stress are referred as stress concentrators, measured by the stress concentration factor $K$. This paper deals with only elastic stress concentration factor. Stress concentration factors are obtained analytically using the elasticity theory or numerically from FEM or experimentally. Unfortunatelly, analytical calculation of stress concentration factors are limited to simple notch shapes. The determination of the stress concentration factor for basic load case and nonstandard shapes of a notch using FEM is presented in this paper (Garrell, 2002).

\section{REFERENCE FEM SIMULATION}

The simplest load case of structural members loading is the uniaxial tension/compression of a bar (Fig.1).

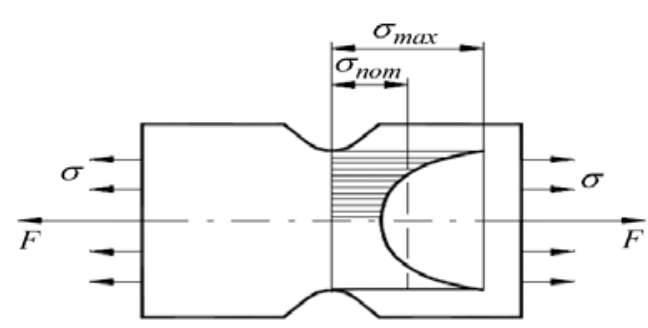

Fig. 1. Stress concentration in bar with notch

The problem of stress concentration factor determination was solved in two steps. Firstly, the finite element model of the round shaft with shoulder fillet in tension (Fig.2) was used for comparison of stress concentration factors obtained from numerical analysis and known from literature (Neuber, 1946, Pilkey, 2005). In the second step, stress concentration factors for round shaft with nonstandart shoulder shape (Fig.5) were determinated using FEM.

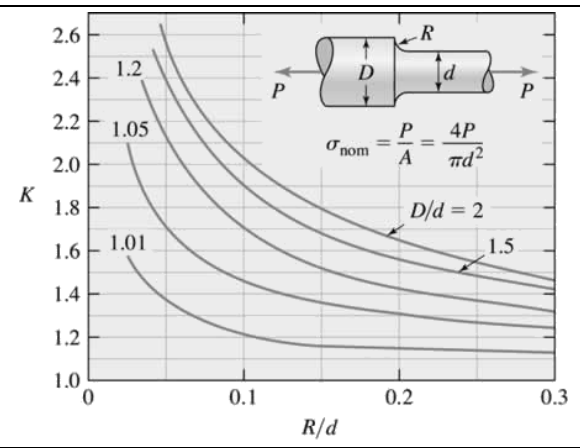

Fig. 2. Stress concentration factor of shoulder fillet in bar of circular cross-section (adapted from Peterson)

\begin{tabular}{|c|c|c|c|c|c|c|}
\hline & \multicolumn{3}{|c|}{$D=150 \mathrm{~mm}$} & \multicolumn{3}{c|}{$D=60 \mathrm{~mm}$} \\
\hline \multirow{2}{*}{$D / d$} & $d$ & $R_{\min }$ & $R_{\max }$ & $d$ & $R_{\min }$ & $R_{\max }$ \\
\cline { 2 - 7 } & {$[\mathrm{mm}]$} & {$[\mathrm{mm}]$} & {$[\mathrm{mm}]$} & {$[\mathrm{mm}]$} & {$[\mathrm{mm}]$} & {$[\mathrm{mm}]$} \\
\hline 3 & 50 & 0.4 & 15 & 20 & 0.4 & 6 \\
\hline 2 & 75 & 0.4 & 22,5 & 30 & 0.4 & 10 \\
\hline 1.5 & 100 & 0.4 & 30 & 40 & 0.4 & 12 \\
\hline
\end{tabular}

Tab. 1. Geometrical parameters of models

To obtain the stress concentration factor as function of selected diameters ratios $D / d$ and radius ratios $R / d$, the axisymmetric finite element model in Fig.3.a with geometric parameters (Tab.1) in ANSYS programme was created. Maximum value of radius $R$ in the simulation models was limited by equations

$$
R_{\max } \leq 0.5(D-d) \text { and/or } R_{\max } \leq 0.3 d
$$

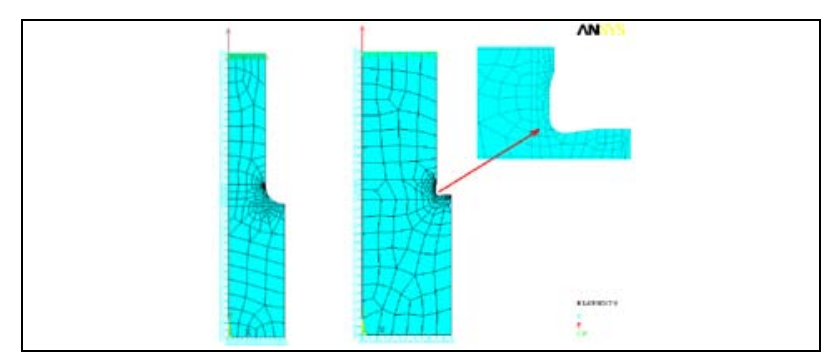

Fig. 3. a) FE model with shoulder fillet, b) FE model with nonstandard shape of shoulder

Stress concentration factor $K$ is defined by (1)

$$
K=\frac{\sigma_{\max }}{\sigma_{\text {nom }}}
$$

where $\sigma_{\max }$ is maximum stress obtained from numerical simulation, and $\sigma_{\text {nom }}$ is the nominal stress calculated by equation $\sigma_{\text {nom }}=P / A=4 P /\left(\pi d^{2}\right)$ with axial force $P=1 \mathrm{~N}$. 
The resulting dependence of stress concentration factor $K$ on ratio $R / d$, and for selected diameter ratios $D / d$ is given in Fig.4. These graphs show good agreement between stress concentration factor obtained by numerical analysis (solid curve) with analytical solution known from literature (dashed curve) (Pilkey, 1997, 2005).

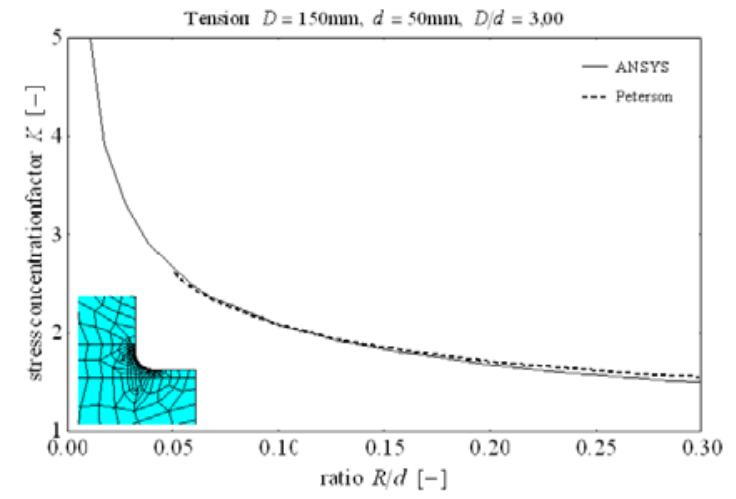

a)

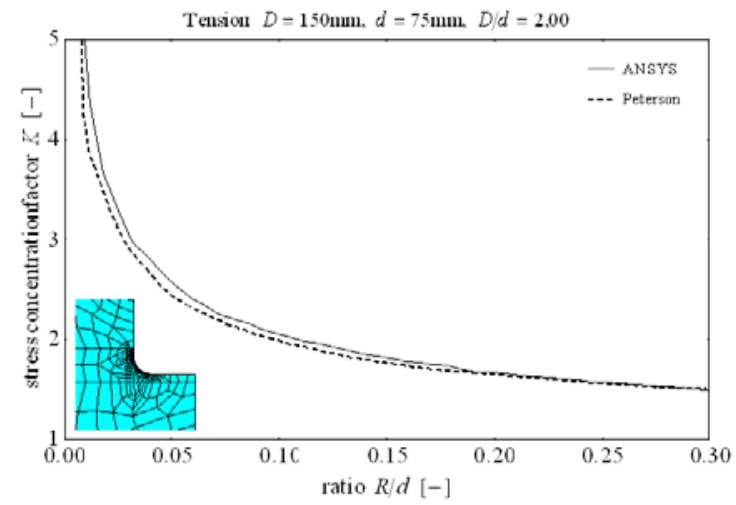

Fig. 4. Stress concentration factors $K$ of round shaft with shoulder fillet for uni-axial tension - ratios: a) $D / d=3.00$, b) $D / d=2.00$

\section{STRESS CONCENTRATION FACTOR BY FEM FOR NONSTANDARD SHAPE OF SHOULDER}

Based on the good correlation of numerical and analytical was determined stress concentration factor for the bar of circular cross-section with modified nonstandard shoulder in Fig.5. This shoulder has constant geometrical shape $(R=1 \mathrm{~mm})$ for restricted range of diameter $d$. For the bar with $D=150 \mathrm{~mm}$, the change of diameter $d=80 \div 130 \mathrm{~mm}$ was considered. For the bar with diameter $D=60 \mathrm{~mm}$, thediameter $d$ was changed in interval $18 \div 50 \mathrm{~mm}$ (see Tab.2).

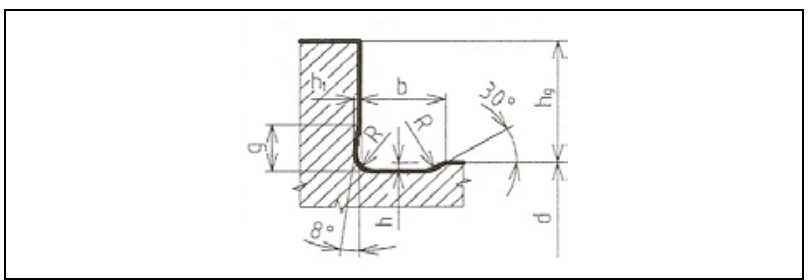

Fig. 5. Shoulder with nonstandard shape

\begin{tabular}{|c|c|c|c|c|c|c|c|}
\hline \multicolumn{2}{|c|}{$d[\mathrm{~mm}]$} & \multicolumn{5}{|c|}{ Parameters of the shoulder [mm] } \\
\hline from & to & $b$ & $g$ & $h$ & $h_{1}$ & $R$ & $h_{\mathrm{g}}$ \\
\hline 18 & 50 & 2.5 & 2.1 & 0.3 & 0.2 & 1 & 4 \\
\hline 80 & 130 & 4 & 3.2 & 0.4 & 0.3 & 1 & 6 \\
\hline
\end{tabular}

Tab. 2. Geometrical parameters of nonstandard shoulder

The results of both numerical analyses are presented in Fig.6 as dependence of stress concentration factor $K$ on diameter ratio $D / d$.

\section{CONCLUSION}

The presented results of numerical experiments in this article show good agreement with reference analytical results. The numerically calculated stress concentration factors for selected cases of round shaft with shoulder fillet are higher as compared to values presented in literature.

The highest difference between numerical results and analytical solution was $5.4 \%$ for bar with $D=150 \mathrm{~mm}$ and diameter ratio $D / d=1.5$. Consequently, numerically calculated stress concentration factor for the fatigue calculations will not reduce the safety level.

In our next work we intend to extend the numerical analysis of stress concentration factor to other basic and combined load states in specimen.

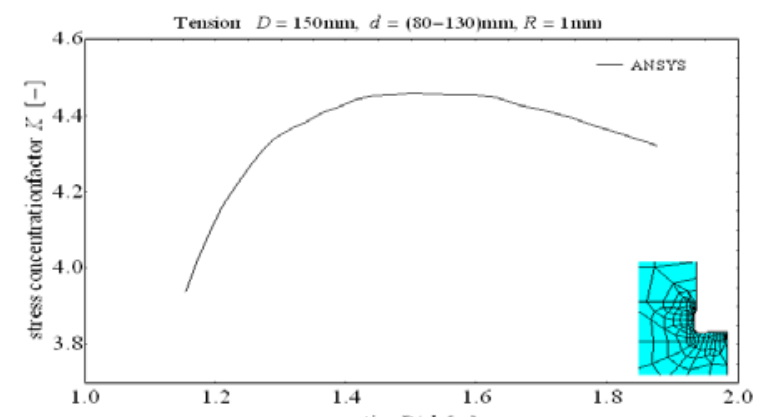

a)

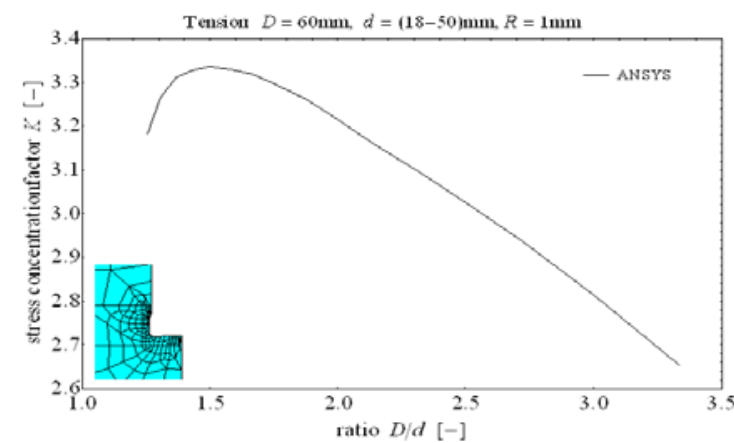

b)

Fig. 6. Stress concentration factors $K$ of round shaft with nonstandard shoulder for uni-axial tension and variation of $d$

\section{ACKNOWLEDGEMENT}

This work has been supported by the Scientific Grant Agency of the Slovak Republic VEGA under the grants No.1/0390/11 and No.1/0256/09.

\section{REFERENCES}

Garrell, M. G.; Shih, A. J.; Lara-Curzio, E. \& Scattergood, R. O. (2002). Finite-Element Analysis of Stress Concentration in ASTM D638 Tension Specimens. Journal of Testing and Evaluation, (ID JTE11402_311), 1-6, Vol. 31, No. 1, ISSN 0090-3973

Neuber, H. (1946). Theory of Notch Stresses: Principles for Exact Stress Calculations. J. W. Edwards, Ann Arbor, Michigan

Pilkey, W. D. \& Pilkey, D. F. (1997). Peterson's stress concentration factors. John Wiley and Sons, Inc., ISBN 0471-53849-3, New York

Pilkey, W. D. (2005) Formulas for Stress, Strain, and Structural Matrices. $2^{\text {nd }}$ ed., John Wiley and Sons, Inc., ISBN 978-1-60119-045-1, New York

Trebuňa, F. \& Šimčák, F. (2004). Odolnost' prvkov mechanických sústav. EMILENA, ISBN 80-8073-148-9, Košice (in Slovak) 